\title{
A map of human circular RNAs in clinically relevant tissues
}

\author{
Philipp G. Maass $1,2,3$ - Petar Glažar ${ }^{2}$ - Sebastian Memczak ${ }^{1,2} \cdot$ Gunnar Dittmar $^{2}$ • \\ Irene Hollfinger ${ }^{1,2}$ • Luisa Schreyer ${ }^{2}$ - Aisha V. Sauer ${ }^{4}$ Okan Toka ${ }^{5,6}$. \\ Alessandro Aiuti ${ }^{4,7} \cdot$ Friedrich C. Luft ${ }^{1,2,8} \cdot$ Nikolaus Rajewsky $^{2}$
}

Received: 2 January 2017 /Revised: 3 August 2017 / Accepted: 18 August 2017 /Published online: 25 August 2017

(C) The Author(s) 2017. This article is an open access publication

\begin{abstract}
Cellular circular RNAs (circRNAs) are generated by head-totail splicing and are present in all multicellular organisms studied so far. Recently, circRNAs have emerged as a large class of RNA which can function as post-transcriptional regulators. It has also been shown that many circRNAs are tissueand stage-specifically expressed. Moreover, the unusual stability and expression specificity make circRNAs important candidates for clinical biomarker research. Here, we present a circRNA expression resource of 20 human tissues highly relevant to disease-related research: vascular smooth muscle cells (VSMCs), human umbilical vein cells (HUVECs), artery endothelial cells (HUAECs), atrium, vena cava, neutrophils,
\end{abstract}

Philipp G. Maass and Petar Glažar contributed equally to the project.

Electronic supplementary material The online version of this article (https://doi.org/10.1007/s00109-017-1582-9) contains supplementary material, which is available to authorized users.

Philipp G. Maass

philipp_maass@harvard.edu

$\bowtie$ Nikolaus Rajewsky

rajewsky@mdc-berlin.de

1 Experimental and Clinical Research Center (ECRC), a joint cooperation between the Charité Medical Faculty and the Max Delbrück Center for Molecular Medicine (MDC), Lindenberger Weg 80, 13125 Berlin, Germany

2 Max Delbrück Center for Molecular Medicine (MDC), Robert-Rössle-Strasse 10, 13125 Berlin, Germany

3 Department of Stem Cell and Regenerative Biology, Harvard University, 7 Divinity Ave, Cambridge, MA 02138, USA platelets, cerebral cortex, placenta, and samples from mesenchymal stem cell differentiation. In eight different samples from a single donor, we found highly tissue-specific circRNA expression. Circular-to-linear RNA ratios revealed that many circRNAs were expressed higher than their linear host transcripts. Among the 71 validated circRNAs, we noticed potential biomarkers. In adenosine deaminase-deficient, severe combined immunodeficiency (ADA-SCID) patients and in Wiskott-Aldrich-Syndrome (WAS) patients' samples, we found evidence for differential circRNA expression of genes that are involved in the molecular pathogenesis of both phenotypes. Our findings underscore the need to assess circRNAs in mechanisms of human disease.
4 Scientific Institute HS Raffaele, San Raffaele Telethon Institute for Gene Therapy (SR-Tiget), 20132 Milan, Italy

5 Department of Pediatric Cardiology, Children's Hospital, Friedrich-Alexander University Erlangen, Loschge Strasse 15, 91054 Erlangen, Germany

6 The German Registry for Congenital Heart Defects, Augustenburger Platz 1, 13353 Berlin, Germany

7 Vita Salute San Raffaele University, Milan, Italy

8 Department of Medicine, Division of Clinical Pharmacology, Vanderbilt University School of Medicine, Nashville, TN 37235, USA 


\section{Key messages}

- circRNA resource catalog of 20 clinically relevant tissues.

- circRNA expression is highly tissue-specific.

- circRNA transcripts are often more abundant than their linear host RNAs.

- circRNAs can be differentially expressed in diseaseassociated genes.

Keywords Circular RNAs · circRNA catalog $\cdot$ Potential biomarker · Human cell types

\section{Introduction}

Cellular circular RNAs (circRNAs) represent a class of singlestranded, unusually stable RNAs originating from $5^{\prime}$-to- $3^{\prime}$ transcription of coding gene exons or long non-coding RNAs (lncRNAs) that produce covalently closed head-to-tail (or backspliced) circularized transcripts [1-4]. Many circRNAs are tissueand developmental stage-specifically expressed $[2,4]$. The circRNA co-transcriptional splicing can compete with linear splicing events and can depend on the binding of the RNA-binding proteins, MBNL1 or QKI, in intronic sequences [5, 6]. Intronic complementary sequences, inter alia repetitive elements, and the RNA-editing protein, ADAR1, were linked to the circularization of exons [7, 8]. Earlier, the circRNAs CDR1as (ciRS-7) and circSRY were shown to exhibit important functions in sponging miRNAs and thereby functioning as post-transcriptional regulators $[2,9,10]$. circRNAs are resistant to the exonuclease RNase $\mathrm{R}$ that solely digests linear transcripts. This feature can be used to validate circRNA candidates by comparing their abundance in the RNase R-treated and untreated samples [11]. circRNAs found in clinical specimens, like blood, reveal that these abundant transcripts could serve as biomarkers [12]. Here, we present a circRNA resource catalog to supplement existing databases with new circRNA transcripts in human cell types. By identifying and validating selected circRNAs in these human tissues relevant to clinical research, we provide multiple examples of abundant and highly tissue-specific circRNA expression in host genes that have been associated with pathogenesis of human disease.

\section{Methods}

\section{Human material}

After approval by the ethics committee (Charité Medical Faculty Berlin and University Clinic Erlangen) and written, informed consent, we obtained human tissues. Mesenchymal stromal cells (MSCs) from a non-affected healthy female (23 years) donor were obtained, characterized, and differentiated as previously described [13]. Fibroblasts from buttocks biopsies of a non-affected male donor ( 25 years) were cultivated until passage six in M-199, supplemented with $20 \%$ FCS. Single samples, each from one donor, were used for sequencing.

Patients or patients' parents signed informed consent on anonymous data collection for research studies conducted on biological samples of patients with primary immunodeficiencies (three Wiskott-Aldrich syndrome samples, four ADA-SCID samples) at San Raffaele Hospital (TIGET02), approved by the San Raffaele Scientific Institute's Ethical Committee. Four T cell lines were generated from peripheral blood mononuclear cells purified by density gradient centrifugation on Ficoll-Hypaque (Nycomed Pharma, Oslo, Norway) and expanded [14].

\section{Tissue preparation}

Adipose tissue was extracted during lipo-aspiration of MSCs from upper abdominal fat. The tissue was rinsed with PBS on Teflon fleece to wash out erythrocytes. Fat spheres were subsequently frozen in liquid nitrogen. Neutrophils were extracted from peripheral whole blood that was supplemented with $30 \%$ of dextran. Cells settled down in a syringe after $30 \mathrm{~min}$. The upper phase was under-laid with histopaque 1083. After centrifugation at $4{ }^{\circ} \mathrm{C}$ for $30 \mathrm{~min}$ at $1200 \mathrm{rpm}$, speed was slowed down to $1050 \mathrm{rpm}$ after $15 \mathrm{~min}$ for another $15 \mathrm{~min}$. Pelleted cells were resuspended in $10 \mathrm{ml}$ water for water lysis. For neutralization, $3.33 \mathrm{ml}$ of $3.6 \% \mathrm{NaCl}$ was added for $10 \mathrm{~min}$. After $10 \mathrm{~min}$ centrifugation at $1050 \mathrm{rpm}$, pelleted neutrophils were resuspended in TRIzol ${ }^{\circledR}$ Reagent (Ambion). Plasma, serum, and platelets were prepared using the Vacutainer system. Whole blood in serum tubes was left undisturbed for clot formation. After 15-30 min, the clot was centrifuged at $1000 \times g$ for $10 \mathrm{~min}$ and the supernatant serum was immediately frozen at $-80^{\circ} \mathrm{C}$. Plasma was prepared from whole blood in EDTA tubes. After a centrifugation at $2000 \times g$ for $10 \mathrm{~min}$, the supernatant was frozen. Citrate tubes were used to obtain platelets. The whole blood was centrifuged for $15 \mathrm{~min}$ at $100 \times g$ without rotor break, preventing platelets' activation. Endothelial progenitor cells (EPCs) were extracted from umbilical cord blood and expanded in vitro using the Lonza EGM ${ }^{\mathrm{TM}}-2$ kit. Human umbilical vein cells (HUVECs) were freshly prepared using standard techniques from umbilical cord and cultivated until passage four in EGM medium (Lonza). Adipose tissue, cortex, placenta, decidua, heart, vena cava, muscle, and umbilical cord were minced using pistils and homogenized with matrix beads in the MP FastPrep-24 Tissue and Cell Homogenizer.

\section{RNA preparation for RNA-seq and qRT-PCR analysis of selected circRNA candidates}

RNA was prepared using TRIzol@ Reagent (Ambion) and phenol/chloroform precipitation. For Illumina sequencing, 
rRNA depletion was done with the RiboMinus ${ }^{\mathrm{TM}}$ eukaryote kit according to manufacturer's recommendation (Life Technologies). Bioanalyzer measurement validated the successful rRNA depletion. The Illumina TruSeq sample preparation kit (v2) was used to generate the libraries for sequencing. For qRT-PCR, total RNA of the identical samples that were used for RNA-seq was digested with RNase

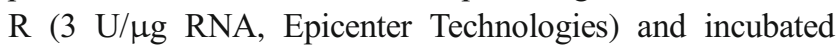
for $15 \mathrm{~min}$ at $37^{\circ} \mathrm{C}$ with following inactivation for $3 \mathrm{~min}$ at $95{ }^{\circ} \mathrm{C}$. To reach similarly effective RNase $\mathrm{R}$ treatment, all samples were treated simultaneously in one approach. Then, the RNA was spiked with $10 \%$ of Caenorhabditis elegans total RNA. After phenol/chloroform precipitation, the RNA was reverse transcribed using RevertAid first strand cDNA synthesis kit (Fermentas) or Maxima RT kit (ThermoFisher Scientific), and SYBR-green quantification (Roche) was performed according to standard protocols on ABI 7500 or StepOnePlus (ThermoScientific). Oligonucleotides flanking the circRNA head-to-tail junctions were designed in Primer3 (v. 0.4.0). RNase R assays were normalized to $C$. elegans eif3d spiked-in RNA and to human GAPDH or Vinculin. For experiments on WAS and ADA-SCID samples, $\triangle \mathrm{Ct}$ was calculated compared to $28 \mathrm{~S}$ rRNA. In general, expression was quantified applying the $\Delta \Delta \mathrm{Ct}$ method. qRT-PCR products were analyzed for amplicon size, specificity, and integrity on $3 \%$ agarose gels; concatemers were not taken into account. Sanger sequencing of qRT-PCR products was performed using the Big Dye $\AA$ Terminator Cycle Sequencing on the 3130xl Genetic Analyzer (ABI) using Gene Mapper ${ }^{\circledR}$ Software Version 4.0. Kit v1.1 (ABI). SeqMan software (Lasergene Version 7.0; DNAStar) was used to analyze the traces.

\section{circRNA detection and annotation}

circRNAs were detected and annotated using the Memczak et al. (2013) pipeline. Human genome reference used for all analyses was hg19 (February 2009, GRCh37), downloaded from UCSC [15]. Upon detection, candidates were annotated using RefSeq and GENCODE v17 gene models. Table S2 and circBase summarize the detected circRNAs across all cell types. Table $\mathrm{S} 2$ harbors genomic positions and annotated host transcripts, sense or antisense strand orientation, circBase IDs, genomic and spliced lengths, number of sequencing reads supporting a head-to-tail junction, as well as the number of either $5^{\prime}$ or $3^{\prime}$ linear reads for each circRNA candidate. We also calculated the circular-to-linear ratios and added the list of samples from other studies listed within circBase.

\section{Data availability}

RNA sequencing data have been deposited in the Gene Expression Omnibus (GEO) under the accession number GSE100242.

\section{circRNA quantification}

The ratio of circular and linear isoforms (circular-to-linear ratio, CLR) was calculated as described in [16]. For each circRNA candidate, we counted the number of reads overlapping the head-to-tail junction, and the number of reads spliced linearly over the $5^{\prime}$ and $3^{\prime}$ sites that gave rise to a circRNA. CLR was expressed as the number of reads spanning the headto-tail junction divided by the number of linear reads mapped over the splice site $\left(5^{\prime}\right.$ or $\left.3^{\prime}\right)$ with the higher read count:

$\mathrm{CLR}=\#$ reads_circular $/ \max (\#$ reads_linear_5-prime, \#reads_linear_3-prime $)$

To avoid division by zero when calculating CLR, a pseudocount of 1 was used where no linearly spliced reads were detected. To estimate the expression levels of circRNA host genes, we mapped RNA-seq libraries to the hg19 reference using STAR [17] and counted the reads mapped to Ensembl (release 75) gene models using the htseq-count tool $[18,19]$.

\section{circRNA expression heatmaps}

circRNAs in Figs. 1c and 2a, c were sorted into three discrete expression classes: (i) "high"- top 10\% (5\% for platelets) expressed, measured by raw read counts, circRNAs in a particular sample; (ii) "detected"-all circRNAs that satisfied the minimum expression threshold of two unique reads overlapping head-to-tail junction; and (iii) "not detected" — circRNAs that were not detected in a particular sample. Only circRNAs that were assigned to "high" category in at least one of the compared samples were plotted.

\section{Differential gene expression}

Differential gene expression analysis was performed using the DESeq package [20]. method="blind" and sharingMode="fit-only" options were used when running the estimateDispersions function, as suggested by the package documentation for experimental designs with no biological replicates. 
Fig. 1 CircRNA expression in clinically relevant human tissues. a CircRNA catalog of human samples with total, new, and unique circRNAs. Samples in bold were derived from one donor. b Distribution of host gene annotation with potential circRNAs. c Differentially expressed top $10 \%$ circRNAs in hierarchical clustering. d CircRNAs from different clusters (C) were validated by qRT-PCR of RNase R-treated samples a

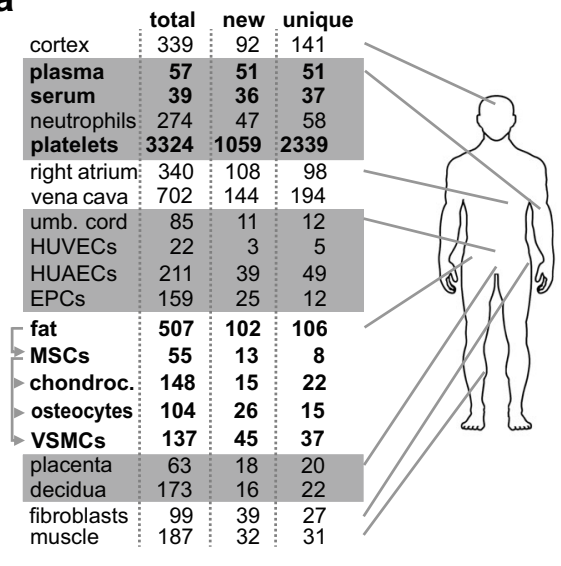

d

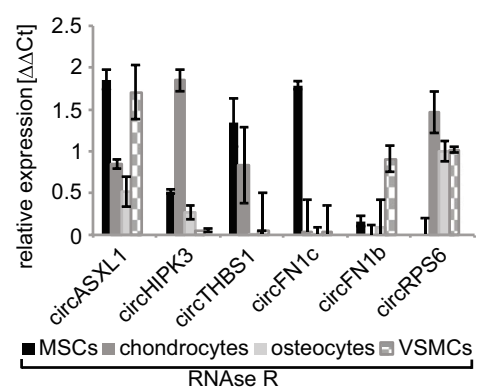

b

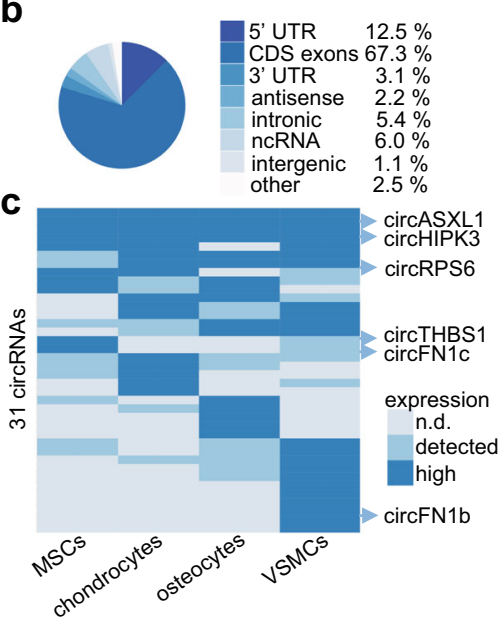

\section{In-solution protein digest}

Peptides were generated using an automated setup [21]. Briefly, samples were reduced with $1 \mathrm{mM}$ tris(2-carboxyethyl) phosphine (TCEP) and free sulfhydryl groups carbamidomethylated using $5.5 \mathrm{mM}$ chloroacetamide. Proteins were pre-digested with $0.5 \mu \mathrm{g}$ sequencing grade endopeptidase LysC (Wako) for $3 \mathrm{~h}$ at room temperature and subsequently diluted with four volumes of $50 \mathrm{mM}$ ammonium-bicarbonate (ABC). Tryptic digestion occurred for $10 \mathrm{~h}$ at room temperature using $1 \mu \mathrm{g}$ sequencing grade trypsin (Promega). The reaction was stopped by adding trifluoroacetic acid (TFA) to a final concentration of $1 \%$ resulting in a final $\mathrm{pH}$ of 2 . The peptides were purified by using $\mathrm{C}_{18}$ stage-tips (3 M) [22].

\section{Mass spectrometry}

Peptides eluted from $\mathrm{C}_{18}$ stage-tips were run on an LC-MS setup. The fractionated and unfractionated samples were measured by LC-MS/MS on a Q Exactive orbitrap mass spectrometer (Thermo) connected to a Proxeon nano-LC system (Thermo) in data-dependent acquisition mode using the top 10 peaks for HCD fragmentation. Peptides were separated on an in-house prepared nano-LC column $(0.074 \mathrm{~mm} \times 250 \mathrm{~mm}$, $3 \mu \mathrm{m}$ Reprosil $\mathrm{C}_{18}$, Dr. Maisch $\left.\mathrm{GmbH}\right)$. Five microlitres of the sample were injected and the peptides were eluted on a 3-h gradient of 4 to $76 \% \mathrm{ACN}$ and $0.1 \% \mathrm{FA}$ in water at flow rates of $0.25 \mu \mathrm{l} / \mathrm{min}$. MS acquisition was performed at a resolution of 70,000 in the scan range from 300 to $1700 \mathrm{~m} / \mathrm{z}, \mathrm{MS} 2$ spectra were collected at a mass resolution of 17,000 with a fixed injection time of $120 \mathrm{~ms}$. Dynamic exclusion was set to $30 \mathrm{~s}$ and the normalized collision energy was specified to 26 . The eluent was directly sprayed into an Q Exactive mass spectrometer (Thermo Fisher Scientific) equipped with a nano electrospray ion source. The recorded spectra were analyzed using MaxQuant software package version 1.5.2.4 [23], with an Andromeda search using the combined UniProt Homo sapiens and Oryctolagus cuniculus databases and a custom database for the circRNA-derived peptides with a false discovery rate of $1 \%$ (peptides and proteins). The fixed and variable modifications were set to carbamidomethylation of cysteines and methionine oxidation, respectively. For further data analysis, the R statistical software package was used (supplement: python script).

\section{Results}

\section{circRNA resource catalog of 20 human tissues}

We generated a circRNA resource catalog for various research interests by sequencing ribosomal RNA-depleted total RNA (Supplemental Table S1). The head-to-tail splice junction identification and the sequence analysis were done according to previously published protocols (Supplemental Fig. S1), [2, 24]. The circRNA catalog can be retrieved in Supplemental 
Fig. 2 CircRNAs are tissuespecific, highly abundant, and the expression can be differential in disease-associated genes. a Clustering of top $10 \%$ differentially expressed circRNAs in umbilical cord, EPCs, HUVECs, and HUAECs and $\mathbf{b}$ their validation. c Tissue-specific expression pattern reflected the overlaps of circRNAs in plasma, serum, neutrophils, and platelets and $\mathbf{d}$ their validation. e Circularto-linear expression ratios revealed highly expressed circRNAs with multiple isoforms. f Validation of circRNAs from disease-relevant genes (GAPDH; Vinculin - linear negative control; hsa-circRNA-5positive control). g CircRNA quantification in three different WAS and four ADA-SCID patients (AFF). The candidates were higher expressed in disease samples than in four controls (bars: mean expression $\pm \mathrm{SEM}$, two technical replicates per WAS or ADA-SCID patient group, except circCDC42BPA: controls $n=6$, WAS $n=5$, Student's $T$ test across samples and replicates, $* * * p<0.001, * * p<0.01$, $* p<0.05$ )
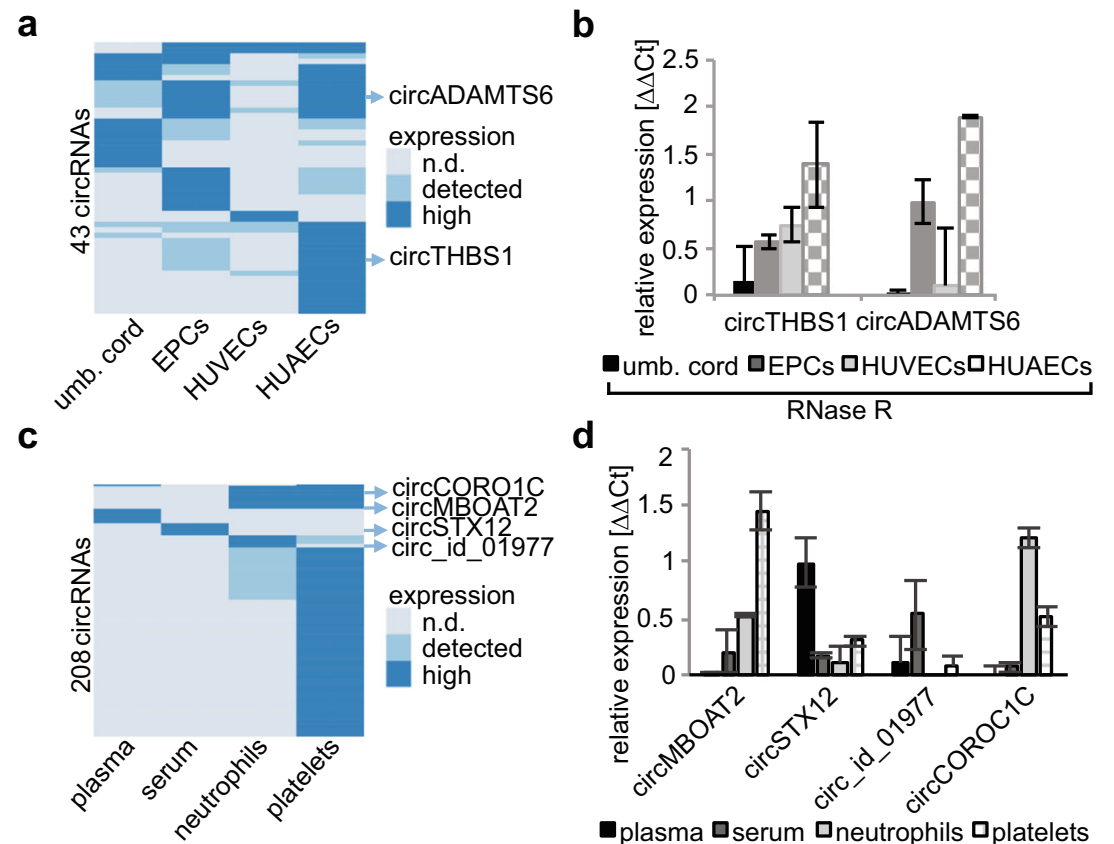

d

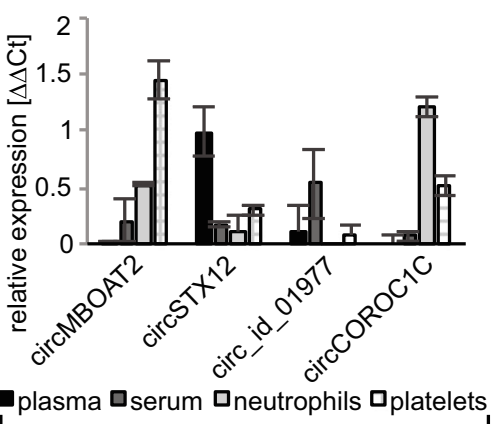

e
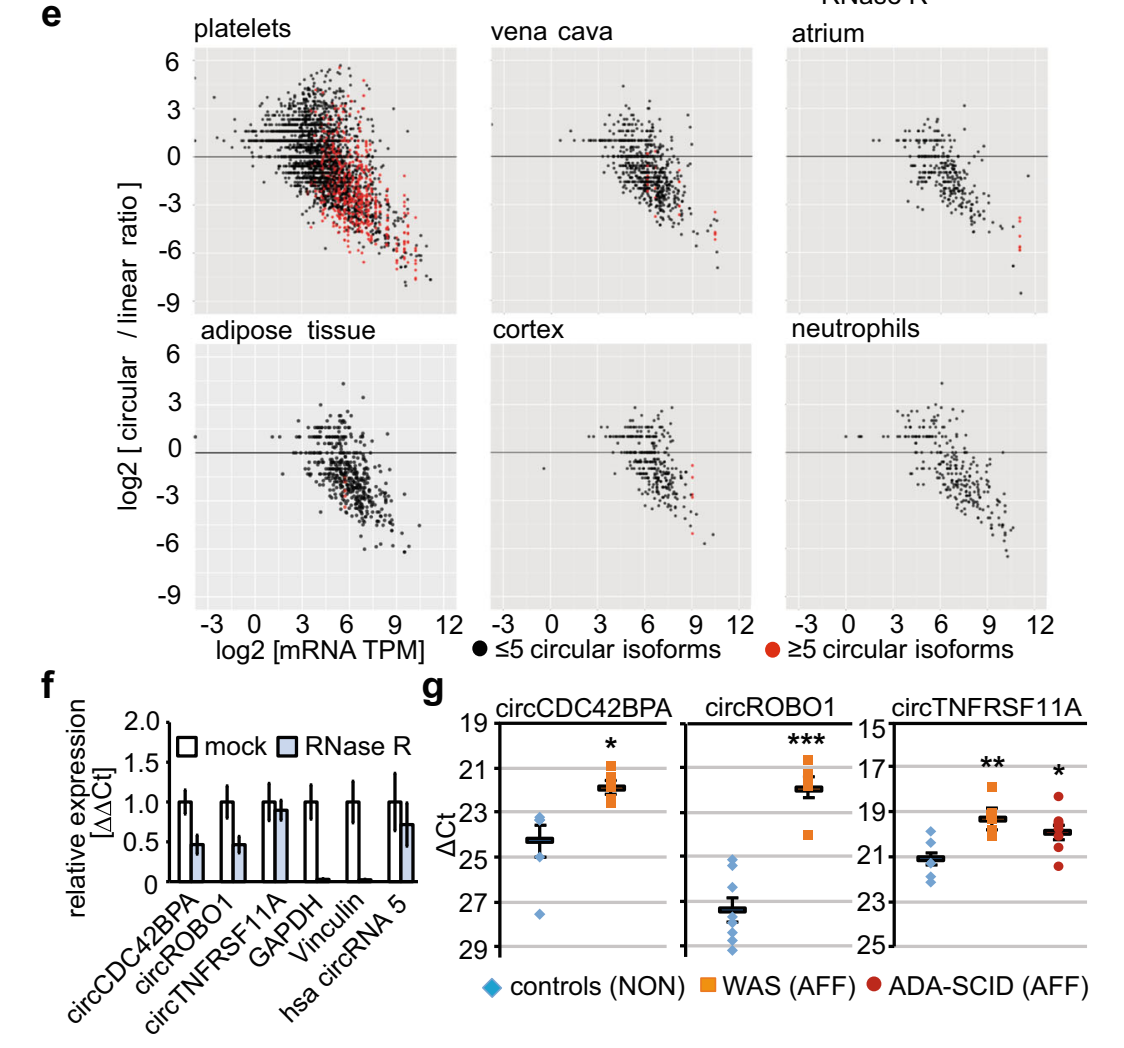

RNase $\mathrm{R}$
Table S2 or circBase, http://www.circbase.org/ [24]. We selected circRNA candidates for validation according to either of the following criteria: (i) the candidate originated from disease or developmental genes (Table 1); (ii) the linear host transcripts have been proposed as biomarkers; (iii) the circRNA was not present in
circBase; (iv) the circRNA was encoded from a lncRNA; or (v) the circRNA showed extraordinary genomic length or expression determined via the read count. In total, we selected 112 candidates, of which we validated 71 circRNAs by RNase R assays (validation rate $63.4 \%$, see "Methods", Supplemental Fig. S2a- 


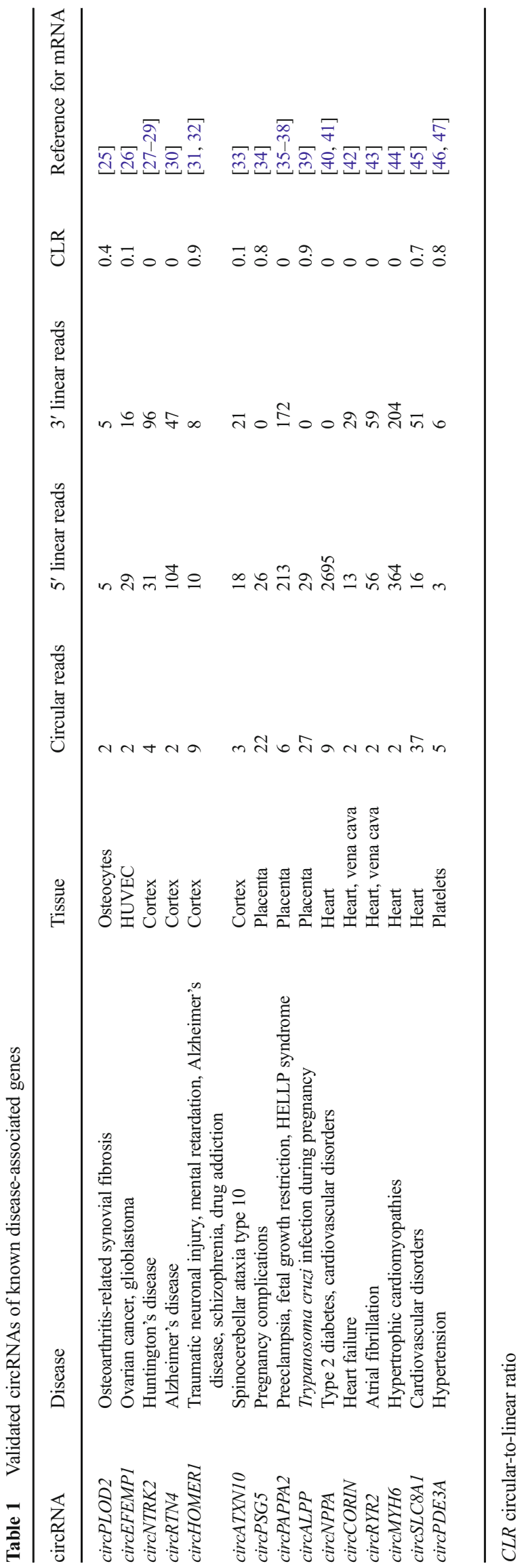

p). We normalized expression values to $C$. elegans eif $3 d$ spiked-in RNA and to human GAPDH or Vinculin. Concatamers in putative circRNA candidates were not taken into account.

Of the 5225 circRNAs, $35.9 \%$ (1878 circRNAs) were new compared to circBase [24]. circRNAs (3841) were unique for the investigated cell types (Fig. 1a). We detected $82.9 \%$ circRNAs in coding genes (exons, $5^{\prime}+3^{\prime}$ UTRs), $2.2 \%$ antisense transcripts, $5.4 \%$ intron-derived circRNAs, $6 \%$ in non-coding genes, and $1.1 \%$ from intergenic regions (Fig. 1b).

\section{circRNA expression in mesenchymal stem cells and MSC-derived cells}

First, we analyzed circRNA expression during MSC differentiation. MSCs were differentiated into proliferating chondrocytes, osteocytes, and vascular smooth muscle cells (VSMCs). Flow cytometry revealed $\mathrm{CD} 105^{+}, \mathrm{CD} 90^{+}, \mathrm{CD} 73^{+}$, HLA-ABC ${ }^{+}, \mathrm{CD}^{2} 1^{-}, \mathrm{CD} 34^{-}, \mathrm{CD} 45^{-}$, and HLA-DR ${ }^{-}$cells and the multi-lineage potential validated MSC properties [46, 48]. In MSCs, we detected 55 circRNAs, in contrast to 148 in MSC-derived chondrocytes, 104 in osteocytes, or 137 in VSMCs. In chondrocytes, we validated a circRNA deriving from PLOD2, a gene which forms collagen crosslinks and was differentially expressed in a model of osteoarthritis-related synovial fibrosis [25]. During the abdominal fat aspiration to obtain MSCs, we additionally harvested adipose tissue that harbors the MSC niches [49]. In the abdominal fat of the same MSC donor, we identified 507 circRNAs. We confirmed a circRNA in $S O R B S 1$, a gene inhibiting the induction of glucose transport by insulin, and two circRNAs in PLIN4, a gene stimulating lipolysis in adipocytes (Supplemental Fig. S2a-d) $[50,51]$. When comparing different MSC-derived tissues, we commonly observed different circRNA isoforms spliced from the same host genes in different MSC-derived cells. Solely eight circRNAs overlapped between adipose tissue, MSCs, and their derived cells (Supplemental Table S2). In eight different tissues of one healthy donor, we excluded interindividual differences and found tissue-restricted expression patterns (Fig. 1a). The absence of circRNA housekeeper and direct comparisons of circRNA expressions between different tissues are controversially discussed endeavors. Thus, we selected the top 10\% circRNA candidates within MSCs and MSCderived cells and clustered 31 circRNAs candidates based on their expression levels: "not detected," "detected" with at least two reads, or "highly expressed" when detected within the top $10 \%$ of the candidates (Fig. 1c). We observed ubiquitous expression for some circRNAs and differential expression regarding the MSC-derived cells. We validated selected circRNA candidates within the cluster analysis showing RNase $\mathrm{R}$ resistance and confirmed the results of clustering (Fig. 1d and Supplemental Fig. 2q). 
circRNAs in disease-associated genes of clinically relevant tissues

Next, we compared physiologically neighboring tissues: umbilical cord, endothelial progenitor cells (EPCs), HUVECs, and HUAECs. Of the 211 circRNAs in HUAECs, only two overlapped with the other tissues. EFEMP1, an angiogenesis promoter, poor prognostic marker in ovarian cancer, and potential therapeutic target in glioblastoma treatment, harbored a circRNA in HUVECs (22 circRNAs) [26, 52]. As previously described, we analyzed the top $10 \%$ of the circRNA candidates. A pool of 43 circRNAs showed differential expression and we validated two circRNAs (Fig. 2a, b and Supplemental Fig. 2q).

In cerebral cortex (339 circRNAs), we validated circRNAs spliced from important cerebral genes. ERC2 is involved in neurotransmitter release and expresses a circRNA [53]. Five circRNA isoforms were found in ATRNL1, a gene regulating the energy homeostasis by melanocortins in the hippocampus [54]. Another circRNA is hosted by NTRK2, a gene that was associated with synaptic dysfunction in Huntington's disease and neuronal differentiation and plasticity in hippocampus [27-29]. We validated a circRNA in RTN4, a gene inhibiting axonal sprouting and modulating Alzheimer's disease progression in a mouse model and one of two predicted circRNAs in HOMER1, a gene that is involved in synaptic activity and various neurological disorders [30-32]. Three circRNAs were expressed in ATXN10 that maintains the survival of neurons, studied in the spinocerebellar ataxia type 10 (Supplemental Fig. S2g) [33].

In placenta, we detected 63 circRNAs, in comparison to 173 in decidua; 15 circRNAs overlapped. We confirmed a circRNA in PSG5, a gene encoding a pregnancy-specific glycoprotein. Low levels indicate pregnancy complications [34]. Severe early onset preeclampsia, fetal growth restriction, and HELLP syndrome were associated with high expression of PAPPA2 that encoded two circRNAs [35-38]. ALPP, less expressed and active in hyperglycemic and diabetic placentas of pregnant women infected with or without Trypanosoma cruzi, harbored a circRNA (Supplemental Fig. S2h) [39].

We also obtained right atrial tissue and vena cava from two children with multiple cardiac defects. Atrium (340 circRNAs) and vena cava (702) had an intersection of 115 circRNAs; 51 overlapped with calf muscle. In atrium, we validated a circRNA in NPPA, a gene that was associated with development of type 2 diabetes [40]. NPPA is reactivated in response to cardiovascular disorders and converted to its active form by CORIN, which harbored four circRNAs (validated in atrium and vena cava) and could be potential biomarkers for heart failure [41, 42]. Atrial fibrillation was linked to the dysfunction of $R Y R 2$, which also produces seven circRNA isoforms in atrium and ten in vena cava [43]. Mutations in myosin heavy chains cause hypertrophic cardiomyopathies [44]. In myosin MYH6, we validated one circRNA. QKI is involved in circRNA biogenesis [6], is responsible for cardiovascular development, and encodes two circRNAs in atrium and vena cava [55]. Alterations in the regulation and expression of SLC8A1 (two circRNAs in atrium) contribute to various cardiovascular symptoms (Supplemental Fig. S2i-k) [45].

\section{circRNAs and their isoforms in platelets}

Platelets expressed 3324 circRNAs. Platelets derive from bone marrow megakaryocytes, lack nuclei and highly abundant mRNA reservoirs, although translational capabilities are intact [56-59]. Previously, high circRNA expression and circRNA properties were described in platelets and this enrichment was associated with transcriptome degradation [60]. We found in our data that platelets harbored much more abundantly expressed circRNAs than any other tissue. For example, circRNA expression in ACVR2A and SMARCA5 was extremely high compared to mRNA (Supplemental Fig. S3). We validated circRNAs in the phosphodiesterases $P D E 3 A$, $P D E 4 D$, and PDE5A. PDEs hydrolyze cAMP and cGMP to control blood vessel relaxation, cardiac contractility, and inhibition of platelet aggregation [61-64]. PDE3A was previously associated with Mendelian hypertension [46, 65]. Moreover, the guanylate cyclase GUCY1B3 converting GTP into cGMP expressed a circRNA (Supplemental Fig. 21-o) [66].

CircRNA expression in plasma (57), serum (39), suggested that circRNAs could be secreted, as it was shown earlier for micro- and other RNAs, and indicated by circRNAs identified in cell culture or serum exosomes [67-71].

In neutrophils (274 circRNAs), TLR6 functions in the innate immune response and harbored a circRNA [72]. Another key component in the immune system expressing a circRNA in neutrophils is $M Y O 1 F$, a class I myosin regulating the host defense against infection [73]. No overlap between plasma, serum, neutrophils, and platelets facilitates the idea of tissuerestricted circRNA expression. For clustering, we used all plasma and serum circRNAs, the top $10 \%$ of neutrophils and the top $5 \%$ of platelets and validated four candidates (Fig. 2c, d and Supplemental Fig. 2q).

Due to the lack of nuclei and the highly abundant circRNAs in platelets, we hypothesized that circRNAs could serve as templates for translation as recently shown for few circRNA examples in human and fly [74, 75]. Thus, we used RNase R-treated whole platelet RNA to perform in vitro translation experiments followed by highly sensitive mass spectrometry. We derived putative open reading frames (ORF) that span head-to-tail junctions of our circRNA candidates. These predictions were compared to mass-spectrometrically detected peptides. Controls were reticulocyte lysate of the in vitro translation kit, non-RNase R-treated whole platelet RNA, and total protein of the same platelet-donor. Although we detected peptides in the RNase R-treated translated sample and in the cell lysate matching circRNAs in platelets, those 
candidates did not overlap with head-to-tail junctions (Supplemental Table S3).

We also investigated circRNA isoforms, since we observed around 100 genes hosting more than five different circRNA isoforms. For example, we detected 18 circRNA isoforms derived either from PTPN12 or TTN in platelets, atrium, and vena cava (Supplemental Fig. S4). We compared circRNA expression directly to linear transcript expression, by counting linearly spliced and head-to-tail spliced reads. The number of reads overlapping with the head-to-tail splice junctions was divided by the number of linear splicing events with identical splice sites (Supplemental Table S2). The calculated value was plotted against the transcript copies per million transcripts (TPM) to describe circRNA expression as circular-to-linear ratio (Fig. 2e). Collectively, we detected high circular-tolinear expression ratios in tissues with abundant circRNA expression, e.g., a platelet circRNA in SMARCA5 had a circularto-linear ratio of 151:1 (Supplemental Fig. S3b).

\section{circRNAs are differentially expressed in disease-relevant genes}

Finally, we demonstrate differential circRNA expression in ADA-SCID and WAS, two primary immunodeficiencies which are caused by mutations in $A D A$ or $W A S$, respectively [76-78]. First, we compared linear transcripts from one patient compared to a non-affected control. We detected significantly differential expression $(p \leq 0.05)$ of 79 mRNAs in ADA-SCID and 19 mRNAs in WAS lymphoblastoid cells (LCLs) (Supplemental Table S4 and Supplemental Fig. S5a, b). The results were consistent with the molecular pathogenesis of both disease phenotypes. For example, upregulated BANK1 $\left(p=2.30 \times 10^{-3}, \log 2\right.$-fold change $\left.(\mathrm{lfc})=3.8\right)$ or PBXIP1 $\left(p=3.53 \times 10^{-2}, 1 \mathrm{fc}=2.4\right)$ mRNAs in ADA-SCID were associated with impaired $\mathrm{B}$ cell receptor-induced calcium mobilization or early blocking of B cell development in the bone marrow (Supplemental Table S4) [79, 80].

We next asked whether these differentially expressed linear transcripts harbor also circRNAs with differential expression between patients and controls. We found a circRNA in ROBO1, a gene upregulated in ADA-SCID (mRNA: $p=9.76 \times 10^{-6}$, $\mathrm{lfc}=5.3$ ) and WAS (mRNA: $p=3.68 \times 10^{-4}, \mathrm{lfc}=8.31$, Supplemental Table S4). Moreover, CDC42BPA expressed an upregulated circRNA in ADA-SCID (mRNA: $p=3.46 \times 10^{-3}$, $1 \mathrm{fc}=4.7)$ and WAS (mRNA: $\left.p=1.93 \times 10^{-3}, 1 \mathrm{fc}=7.4\right)$. Notably, ROBO1 and CDC42 are linked to the pathogenesis of WAS. Slit2 and Robo- 1 complexes have been described to inhibit the CXCR4/CXCL12-mediated chemotaxis of T cells [81]. Moreover, ROBO1 and ROBO4 bind WAS to induce filopodia formation [82, 83]. Cdc42-dependent WAS activation was also reported $[84,85]$. CDC42 is a major regulator of podosome formation and remodels actin during B cell signaling [86, 87], whereas $C D C 42 B P A$ is a downstream effector of CDC42 [88]. B cell signaling is impaired both in ADA-SCID [79, 80] and WAS $[89,90]$. In ADA-SCID, we found a circRNA in TNFRSF11A (mRNA: $p=8.28 \times 10^{-3}$, lfc $=3.3$ ) TNF receptors participate in several pathways altered in ADA-SCID [14]. We first validated the circRNAs in ROBO1, CDC42BPA, and TNFRSF11A (Fig. 2f and Supplemental S6a) and tested next their differential expression in three WAS and four ADA-SCID samples, compared to four non-affected LCL samples (Fig. 2g). circRNA expression of phenotypically relevant genes was higher in the disease samples (Fig. 2g).

\section{Discussion}

Collectively, we provide a circRNA catalog of human tissues relevant to various fields of clinical research. We provide evidence that circRNAs could serve as biomarkers and that circRNA expression profiles could be directly linked to clinically apparent phenotypes. We focused on detecting circRNAs in various single samples. For further analyzing the proposed circRNA candidates as suitable biomarkers, broader studies addressing tissue specificity vs. donor specificity are needed. Our data corroborate recent findings that circRNA expression is highly tissue-specific $[2,16,91]$. We did not find evidence that platelet circRNAs were translated; however, our result does not provide conclusive evidence that circRNAs are not translated, as it highly depends on mass-spec sensitivity. As previously suggested [60], a resistance to RNA degradation can explain the high abundance of circRNAs in platelets. In the absence of transcription, the detected circRNAs could function independently of transcriptional regulation.

As discussed previously [2], circRNAs uncovered in this study could contribute to regulatory networks governing coding gene expression by acting as miRNA target decoys, RNAbinding protein (RBP) sponges, scaffolding molecules, and transcriptional regulators. A circRNA function is further supported by the conserved nature of circRNA expression and the tissue-specific and regulated abundance [16]. Although we can only speculate that currently disclosed circRNAs influence the functions of their linear counterparts, these new isoforms need to be considered when investigating diseaserelevant genes. Since circRNA biogenesis can compete with pre-mRNA splicing, this opens up the possibility that the mRNA output from those, oftentimes well studied genes, is controlled by the hitherto unknown circRNA [5].

Acknowledgments We thank K. Mai, G. Rahn, Y. Wefeld-Neuenfeld, M.-B. Köhler, S. Scaramuzza, and S. Giannelli for technical assistance. R. Kettritz, D. Müller, F. le Noble, and J. Meier kindly provided human samples. The Deutsche Forschungsgemeinschaft (DFG) supported P.G.M., F.C.L., and N.R. (MA-5028/1-3, LU-435/15-1, RA-838/7-1). P.G. was supported by Deutsches Epigenom Programm (DEEP). The 
Italian Ministry of Health supported A.V.S. (GR-2011-02346985). The MDC and the ECRC provided the necessary infrastructure.

\section{Compliance with ethical standards}

Conflict of interest The authors have nothing to disclose.

Open Access This article is distributed under the terms of the Creative Commons Attribution 4.0 International License (http:// creativecommons.org/licenses/by/4.0/), which permits unrestricted use, distribution, and reproduction in any medium, provided you give appropriate credit to the original author(s) and the source, provide a link to the Creative Commons license, and indicate if changes were made.

\section{References}

1. Jeck WR, Sorrentino JA, Wang K, Slevin MK, Burd CE, Liu J, Marzluff WF, Sharpless NE (2013) Circular RNAs are abundant, conserved, and associated with ALU repeats. RNA 19(2):141-157

2. Memczak S, Jens M, Elefsinioti A, Torti F, Krueger J, Rybak A, Maier L, Mackowiak SD, Gregersen LH, Munschauer M et al (2013) Circular RNAs are a large class of animal RNAs with regulatory potency. Nature 495(7441):333-338

3. Salzman J, Gawad C, Wang PL, Lacayo N, Brown PO (2012) Circular RNAs are the predominant transcript isoform from hundreds of human genes in diverse cell types. PLoS One 7(2):e30733

4. Salzman J, Chen RE, Olsen MN, Wang PL, Brown PO (2013) Celltype specific features of circular RNA expression. PLoS Genet 9(9): e1003777

5. Ashwal-Fluss R, Meyer M, Pamudurti NR, Ivanov A, Bartok O, Hanan M, Evantal N, Memczak S, Rajewsky N, Kadener S (2014) circRNA biogenesis competes with pre-mRNA splicing. Mol Cell 56(1):55-66

6. Conn SJ, Pillman KA, Toubia J, Conn VM, Salmanidis M, Phillips CA, Roslan S, Schreiber AW, Gregory PA, Goodall GJ (2015) The RNA binding protein quaking regulates formation of circRNAs. Cell 160(6):1125-1134

7. Ivanov A, Memczak S, Wyler E, Torti F, Porath HT, Orejuela MR, Piechotta M, Levanon EY, Landthaler M, Dieterich C et al (2015) Analysis of intron sequences reveals hallmarks of circular RNA biogenesis in animals. Cell Rep 10(2):170-177

8. Zhang XO, Wang HB, Zhang Y, Lu X, Chen LL, Yang L (2014) Complementary sequence-mediated exon circularization. Cell 159(1):134-147

9. Hansen TB, Jensen TI, Clausen BH, Bramsen JB, Finsen B, Damgaard CK, Kjems J (2013) Natural RNA circles function as efficient microRNA sponges. Nature 495(7441):384-388

10 Piwecka M, Glažar P, Hernandez-Miranda LR, Memczak S, Wolf SA, Rybak-Wolf A, Filipchyk A et al (2017) Loss of a Mammalian Circular RNA Locus Causes miRNA Deregulation and Affects Brain Function. Science. https://doi.org/10.1126/science.aam8526

11. Suzuki H, Zuo Y, Wang J, Zhang MQ, Malhotra A, Mayeda A (2006) Characterization of RNase R-digested cellular RNA source that consists of lariat and circular RNAs from pre-mRNA splicing. Nucleic Acids Res 34(8):e63

12. Memczak S, Papavasileiou P, Peters O, Rajewsky N (2015) Identification and characterization of circular RNAs as a new class of putative biomarkers in human blood. PLoS One 10(10): e0141214

13. Maass PG, Aydin A, Luft FC, Schachterle C, Weise A, Stricker S, Lindschau C, Vaegler M, Qadri F, Toka HR et al (2015) PDE3A mutations cause autosomal dominant hypertension with brachydactyly. Nat Genet. https://doi.org/10.1038/ng.3302
14. Cassani B, Mirolo M, Cattaneo F, Benninghoff U, Hershfield M, Carlucci F, Tabucchi A, Bordignon C, Roncarolo MG, Aiuti A (2008) Altered intracellular and extracellular signaling leads to impaired T-cell functions in ADA-SCID patients. Blood 111(8):42094219

15. Rosenbloom KR, Armstrong J, Barber GP, Casper J, Clawson H, Diekhans M, Dreszer TR, Fujita PA, Guruvadoo L, Haeussler M et al (2015) The UCSC Genome Browser database: 2015 update. Nucleic Acids Res 43(Database issue):D670-D681

16. Rybak-Wolf A, Stottmeister C, Glazar P, Jens M, Pino N, Giusti S, Hanan M, Behm M, Bartok O, Ashwal-Fluss R et al (2015) Circular RNAs in the mammalian brain are highly abundant, conserved, and dynamically expressed. Mol Cell 58(5):870-885

17. Dobin A, Davis CA, Schlesinger F, Drenkow J, Zaleski C, Jha S, Batut P, Chaisson M, Gingeras TR (2013) STAR: ultrafast universal RNA-seq aligner. Bioinformatics 29(1):15-21

18. Flicek P, Amode MR, Barrell D, Beal K, Billis K, Brent S, Carvalho-Silva D, Clapham P, Coates G, Fitzgerald S et al (2014) Ensembl 2014. Nucleic Acids Res 42(Database issue):D749-D755

19. Anders S, Pyl PT, Huber W (2015) HTSeq - a Python framework to work with high-throughput sequencing data. Bioinformatics 31(2):166-169

20. Anders S, Huber W (2010) Differential expression analysis for sequence count data. Genome Biol 11(10):R106

21. Kanashova T, Popp O, Orasche J, Karg E, Harndorf H, Stengel B, Sklorz M, Streibel T, Zimmermann R, Dittmar G (2015) Differential proteomic analysis of mouse macrophages exposed to adsorbate-loaded heavy fuel oil derived combustion particles using an automated sample-preparation workflow. Anal Bioanal Chem 407(20):5965-5976

22. Rappsilber J, Mann M, Ishihama Y (2007) Protocol for micro-purification, enrichment, pre-fractionation and storage of peptides for proteomics using StageTips. Nat Protoc 2(8):1896-1906

23. Cox J, Mann M (2008) MaxQuant enables high peptide identification rates, individualized p.p.b.-range mass accuracies and proteome-wide protein quantification. Nat Biotechnol 26(12):1367-1372

24. Glazar P, Papavasileiou P, Rajewsky N (2014) circBase: a database for circular RNAs. RNA 20(11):1666-1670

25. Remst DF, Blom AB, Vitters EL, Bank RA, van den Berg WB, Blaney Davidson EN, van der Kraan PM (2014) Gene expression analysis of murine and human osteoarthritis synovium reveals elevation of transforming growth factor beta-responsive genes in osteoarthritis-related fibrosis. Arthritis Rheumatol 66(3):647-656

26. Chen J, Wei D, Zhao Y, Liu X, Zhang J (2013) Overexpression of EFEMP1 correlates with tumor progression and poor prognosis in human ovarian carcinoma. PLoS One 8(11):e78783

27. Bramham CR (2008) Local protein synthesis, actin dynamics, and LTP consolidation. Curr Opin Neurobiol 18(5):524-531

28. Plotkin JL, Day M, Peterson JD, Xie Z, Kress GJ, Rafalovich I, Kondapalli J, Gertler TS, Flajolet M, Greengard P et al (2014) Impaired TrkB receptor signaling underlies corticostriatal dysfunction in Huntington's disease. Neuron 83(1):178-188

29. Yang J, Harte-Hargrove LC, Siao CJ, Marinic T, Clarke R, Ma Q, Jing D, Lafrancois JJ, Bath KG, Mark W et al (2014) proBDNF negatively regulates neuronal remodeling, synaptic transmission, and synaptic plasticity in hippocampus. Cell Rep 7(3):796-806

30. Masliah E, Xie F, Dayan S, Rockenstein E, Mante M, Adame A, Patrick CM, Chan AF, Zheng B (2010) Genetic deletion of Nogo/ Rtn 4 ameliorates behavioral and neuropathological outcomes in amyloid precursor protein transgenic mice. Neuroscience 169(1): 488-494

31. Fei F, Rao W, Zhang L, Chen BG, Li J, Fei Z, Chen Z (2014) Downregulation of Homer1b/c improves neuronal survival after traumatic neuronal injury. Neuroscience 267:187-194 
32. Luo P, Li X, Fei Z, Poon W (2012) Scaffold protein Homer 1: implications for neurological diseases. Neurochem Int 61(5):731738

33. Marz P, Probst A, Lang S, Schwager M, Rose-John S, Otten U, Ozbek S (2004) Ataxin-10, the spinocerebellar ataxia type 10 neurodegenerative disorder protein, is essential for survival of cerebellar neurons. J Biol Chem 279(34):35542-35550

34. Camolotto S, Racca A, Rena V, Nores R, Patrito LC, GentiRaimondi S, Panzetta-Dutari GM (2010) Expression and transcriptional regulation of individual pregnancy-specific glycoprotein genes in differentiating trophoblast cells. Placenta 31(4):312-319

35. Buimer M, Keijser R, Jebbink JM, Wehkamp D, van Kampen AH, Boer K, van der Post JA, Ris-Stalpers C (2008) Seven placental transcripts characterize HELLP-syndrome. Placenta 29(5):444-453

36. Macintire K, Tuohey L, Ye L, Palmer K, Gantier M, Tong S, Kaitu'u-Lino TJ (2014) PAPPA2 is increased in severe early onset pre-eclampsia and upregulated with hypoxia. Reprod Fertil Dev 26(2):351-357

37. Varkonyi T, Nagy B, Fule T, Tarca AL, Karaszi K, Schonleber J, Hupuczi P, Mihalik N, Kovalszky I, Rigo J Jr et al (2011) Microarray profiling reveals that placental transcriptomes of earlyonset HELLP syndrome and preeclampsia are similar. Placenta 32(Suppl):S21-S29

38. Whitehead CL, Walker SP, Ye L, Mendis S, Kaitu'u-Lino TJ, Lappas M, Tong S (2013) Placental specific mRNA in the maternal circulation are globally dysregulated in pregnancies complicated by fetal growth restriction. J Clin Endocrinol Metab 98(3):E429-E436

39. Mezzano L, Sartori MJ, Lin S, Repossi G, de Fabro SP (2005) Placental alkaline phosphatase (PLAP) study in diabetic human placental villi infected with Trypanosoma cruzi. Placenta 26(1): 85-92

40. Jujic A, Nilsson PM, Engstrom G, Hedblad B, Melander O, Magnusson M (2014) Atrial natriuretic peptide and type 2 diabetes development - biomarker and genotype association study. PLoS One 9(2):e89201

41. Houweling AC, van Borren MM, Moorman AF, Christoffels VM (2005) Expression and regulation of the atrial natriuretic factor encoding gene Nppa during development and disease. Cardiovasc Res 67(4):583-593

42. Dong N, Chen S, Wang W, Zhou Y, Wu Q (2012) Corin in clinical laboratory diagnostics. Clin. Chim. Acta 413(3-4):378-383

43. Dobrev D, Voigt N, Wehrens XH (2011) The ryanodine receptor channel as a molecular motif in atrial fibrillation: pathophysiological and therapeutic implications. Cardiovasc Res 89(4):734-743

44. Jiang J, Wakimoto H, Seidman JG, Seidman CE (2013) Allelespecific silencing of mutant Myh6 transcripts in mice suppresses hypertrophic cardiomyopathy. Science 342(6154):111-114

45. Khananshvili D (2013) The SLC8 gene family of sodium-calcium exchangers $(\mathrm{NCX})$ - structure, function, and regulation in health and disease. Mol Asp Med 34(2-3):220-235

46. Maass PG, Aydin A, Luft FC, Schachterle C, Weise A, Stricker S, Lindschau C, Vaegler M, Qadri F, Toka HR et al (2015) PDE3A mutations cause autosomal dominant hypertension with brachydactyly. Nat Genet 47(6):647-653

47. Toka O, Tank J, Schachterle C, Aydin A, Maass PG, Elitok S, Bartels-Klein E, Hollfinger I, Lindschau C, Mai K et al (2015) Clinical effects of phosphodiesterase 3A mutations in inherited hypertension with brachydactyly. Hypertension. https://doi.org/10. 1161/HYPERTENSIONAHA. 115.06000

48. Salem HK, Thiemermann C (2010) Mesenchymal stromal cells: current understanding and clinical status. Stem Cells 28(3):585596

49. Vermette M, Trottier V, Menard V, Saint-Pierre L, Roy A, Fradette J (2007) Production of a new tissue-engineered adipose substitute from human adipose-derived stromal cells. Biomaterials 28(18): $2850-2860$
50. Baumann CA, Ribon V, Kanzaki M, Thurmond DC, Mora S, Shigematsu S, Bickel PE, Pessin JE, Saltiel AR (2000) CAP defines a second signalling pathway required for insulin-stimulated glucose transport. Nature 407(6801):202-207

51. Clifford GM, Londos C, Kraemer FB, Vernon RG, Yeaman SJ (2000) Translocation of hormone-sensitive lipase and perilipin upon lipolytic stimulation of rat adipocytes. J Biol Chem 275(7): 5011-5015

52. Hiddingh L, Tannous BA, Teng J, Tops B, Jeuken J, Hulleman E, Boots-Sprenger SH, Vandertop WP, Noske DP, Kaspers GJ et al (2014) EFEMP1 induces gamma-secretase/Notch-mediated temozolomide resistance in glioblastoma. Oncotarget 5(2):363374

53. Takao-Rikitsu E, Mochida S, Inoue E, Deguchi-Tawarada M, Inoue M, Ohtsuka T, Takai Y (2004) Physical and functional interaction of the active zone proteins, CAST, RIM1, and Bassoon, in neurotransmitter release. J Cell Biol 164(2):301-311

54. Haqq AM, Rene P, Kishi T, Khong K, Lee CE, Liu H, Friedman JM, Elmquist JK, Cone RD (2003) Characterization of a novel binding partner of the melanocortin-4 receptor: attractin-like protein. Biochem J 376(Pt 3):595-605

55. Justice MJ, Hirschi KK (2010) The role of quaking in mammalian embryonic development. Adv Exp Med Biol 693:82-92

56. Bugert P, Dugrillon A, Gunaydin A, Eichler H, Kluter H (2003) Messenger RNA profiling of human platelets by microarray hybridization. Thromb Haemost 90(4):738-748

57. Gnatenko DV, Dunn JJ, McCorkle SR, Weissmann D, Perrotta PL, Bahou WF (2003) Transcript profiling of human platelets using microarray and serial analysis of gene expression. Blood 101(6): 2285-2293

58. Machlus KR, Thon JN, Italiano JE Jr (2014) Interpreting the developmental dance of the megakaryocyte: a review of the cellular and molecular processes mediating platelet formation. Br J Haematol 165(2):227-236

59. Rowley JW, Oler AJ, Tolley ND, Hunter BN, Low EN, Nix DA, Yost CC, Zimmerman GA, Weyrich AS (2011) Genome-wide RNA-seq analysis of human and mouse platelet transcriptomes. Blood 118(14):e101-e111

60. Alhasan AA, Izuogu OG, Al-Balool HH, Steyn JS, Evans A, Colzani M, Ghevaert C, Mountford JC, Marenah L, Elliott DJ et al (2016) Circular RNA enrichment in platelets is a signature of transcriptome degradation. Blood 127(9):e1-e11

61. Beca S, Helli PB, Simpson JA, Zhao D, Farman GP, Jones PP, Tian X, Wilson LS, Ahmad F, Chen SR et al (2011) Phosphodiesterase 4D regulates baseline sarcoplasmic reticulum $\mathrm{Ca} 2+$ release and cardiac contractility, independently of L-type $\mathrm{Ca} 2+$ current. Circ Res 109(9): 1024-1030

62. Hunter RW, Mackintosh C, Hers I (2009) Protein kinase Cmediated phosphorylation and activation of PDE3A regulate cAMP levels in human platelets. J Biol Chem 284(18):12339 12348

63. Mullershausen F, Friebe A, Feil R, Thompson WJ, Hofmann F, Koesling D (2003) Direct activation of PDE5 by cGMP: longterm effects within NO/cGMP signaling. J Cell Biol 160(5):719 727

64. Schwarz UR, Walter U, Eigenthaler M (2001) Taming platelets with cyclic nucleotides. Biochem Pharmacol 62(9):1153-1161

65. Toka O, Tank J, Schachterle C, Aydin A, Maass PG, Elitok S, Bartels-Klein E, Hollfinger I, Lindschau C, Mai K et al (2015) Clinical effects of phosphodiesterase 3A mutations in inherited hypertension with brachydactyly. Hypertension 66(4):800-808

66. Zabel U, Weeger M, La M, Schmidt HH (1998) Human soluble guanylate cyclase: functional expression and revised isoenzyme family. Biochem J 335(Pt 1):51-57

67. Koh W, Pan W, Gawad C, Fan HC, Kerchner GA, Wyss-Coray T, Blumenfeld YJ, El-Sayed YY, Quake SR (2014) Noninvasive 
in vivo monitoring of tissue-specific global gene expression in humans. Proc Natl Acad Sci U S A 111(20):7361-7366

68. Lasda E, Parker R (2016) Circular RNAs co-precipitate with extracellular vesicles: a possible mechanism for circRNA clearance. PLoS One 11(2):e0148407

69. Valadi H, Ekstrom K, Bossios A, Sjostrand M, Lee JJ, Lotvall JO (2007) Exosome-mediated transfer of mRNAs and microRNAs is a novel mechanism of genetic exchange between cells. Nat Cell Biol 9(6):654-659

70. Wang K, Zhang S, Weber J, Baxter D, Galas DJ (2010) Export of microRNAs and microRNA-protective protein by mammalian cells. Nucleic Acids Res 38(20):7248-7259

71. Li Y, Zheng Q, Bao C, Li S, Guo W, Zhao J, Chen D, Gu J, He X, Huang S (2015) Circular RNA is enriched and stable in exosomes: a promising biomarker for cancer diagnosis. Cell Res 25(8):981-984

72. Jang TH, Park HH (2014) Crystal structure of TIR domain of TLR6 reveals novel dimeric interface of TIR-TIR interaction for toll-like receptor signaling pathway. J Mol Biol 426(19):3305-3313

73. Kim SV, Mehal WZ, Dong X, Heinrich V, Pypaert M, Mellman I, Dembo M, Mooseker MS, Wu D, Flavell RA (2006) Modulation of cell adhesion and motility in the immune system by Myo1f. Science 314(5796):136-139

74. Legnini I, Di Timoteo G, Rossi F, Morlando M, Briganti F, Sthandier O, Fatica A, Santini T, Andronache A, Wade M et al (2017) Circ-ZNF609 is a circular RNA that can be translated and functions in Myogenesis. Mol Cell 66(1):22-37 e29

75. Pamudurti NR, Bartok O, Jens M, Ashwal-Fluss R, Stottmeister C, Ruhe L, Hanan M, Wyler E, Perez-Hernandez D, Ramberger E et al (2017) Translation of CircRNAs. Mol Cell 66(1):9-21 e27

76. Arredondo-Vega FX, Santisteban I, Daniels S, Toutain S, Hershfield MS (1998) Adenosine deaminase deficiency: genotype-phenotype correlations based on expressed activity of 29 mutant alleles. Am J Hum Genet 63(4):1049-1059

77. Jin Y, Mazza C, Christie JR, Giliani S, Fiorini M, Mella P, Gandellini F, Stewart DM, Zhu Q, Nelson DL et al (2004) Mutations of the Wiskott-Aldrich Syndrome Protein (WASP): hotspots, effect on transcription, and translation and phenotype/ genotype correlation. Blood 104(13):4010-4019

78. Sauer AV, Di Lorenzo B, Carriglio N, Aiuti A (2014) Progress in gene therapy for primary immunodeficiencies using lentiviral vectors. Curr Opin Allergy Clin Immunol 14(6):527-534

79. Brigida I, Sauer AV, Ferrua F, Giannelli S, Scaramuzza S, Pistoia V, Castiello MC, Barendregt BH, Cicalese MP, Casiraghi M et al (2014) B-cell development and functions and therapeutic options in adenosine deaminase-deficient patients. J Allergy Clin Immunol 133(3):799-806 e710
80. Sauer AV, Morbach H, Brigida I, Ng YS, Aiuti A, Meffre E (2012) Defective B cell tolerance in adenosine deaminase deficiency is corrected by gene therapy. J Clin Invest 122(6):2141-2152

81. Prasad A, Qamri Z, Wu J, Ganju RK (2007) Slit-2/Robo-1 modulates the CXCL12/CXCR4-induced chemotaxis of T cells. J Leukoc Biol 82(3):465-476

82. Prasad A, Kuzontkoski PM, Shrivastava A, Zhu W, Li DY, Groopman JE (2012) Slit2N/Robo1 inhibit HIV-gp120-induced migration and podosome formation in immature dendritic cells by sequestering LSP1 and WASp. PLoS One 7(10):e48854

83. Sheldon H, Andre M, Legg JA, Heal P, Herbert JM, Sainson R, Sharma AS, Kitajewski JK, Heath VL, Bicknell R (2009) Active involvement of Robo1 and Robo4 in filopodia formation and endothelial cell motility mediated via WASP and other actin nucleationpromoting factors. FASEB J. 23(2):513-522

84. Cammer M, Gevrey JC, Lorenz M, Dovas A, Condeelis J, Cox D (2009) The mechanism of CSF-1-induced Wiskott-Aldrich syndrome protein activation in vivo: a role for phosphatidylinositol 3kinase and Cdc42. J Biol Chem 284(35):23302-23311

85. Takenawa T, Suetsugu S (2007) The WASP-WAVE protein network: connecting the membrane to the cytoskeleton. Nat Rev Mol Cell Biol 8(1):37-48

86. Burbage M, Keppler SJ, Gasparrini F, Martinez-Martin N, Gaya M, Feest C, Domart MC, Brakebusch C, Collinson L, Bruckbauer A et al (2015) Cdc42 is a key regulator of B cell differentiation and is required for antiviral humoral immunity. J Exp Med 212(1):53-72

87. Kim AS, Kakalis LT, Abdul-Manan N, Liu GA, Rosen MK (2000) Autoinhibition and activation mechanisms of the Wiskott-Aldrich syndrome protein. Nature 404(6774):151-158

88. Leung T, Chen XQ, Tan I, Manser E, Lim L (1998) Myotonic dystrophy kinase-related Cdc42-binding kinase acts as a $\mathrm{Cdc} 42$ effector in promoting cytoskeletal reorganization. Mol Cell Biol 18(1): 130-140

89. Pala F, Morbach H, Castiello MC, Schickel JN, Scaramuzza S, Chamberlain N, Cassani B, Glauzy S, Romberg N, Candotti F et al (2015) Lentiviral-mediated gene therapy restores B cell tolerance in Wiskott-Aldrich syndrome patients. J Clin Invest 125(10): 3941-3951

90. Castiello MC, Scaramuzza S, Pala F, Ferrua F, Uva P, Brigida I, Sereni L, van der Burg M, Ottaviano G, Albert MH et al (2015) Bcell reconstitution after lentiviral vector-mediated gene therapy in patients with Wiskott-Aldrich syndrome. J Allergy Clin Immunol 136(3):692-702 e692

91. Szabo L, Morey R, Palpant NJ, Wang PL, Afari N, Jiang C, Parast MM, Murry CE, Laurent LC, Salzman J (2015) Statistically based splicing detection reveals neural enrichment and tissue-specific induction of circular RNA during human fetal development. Genome Biol 16:126 